\title{
Workplace Harassment of Working Women: A Case Study Of District Dera Ghazi Khan (DG-Kan)
}

\author{
Aisha Khan ${ }^{* 1}$ and Uzma Masroor \\ ${ }^{1}$ Department Sociology, The Women University Multan, Pakistan \\ ${ }^{2}$ Department Sociology, International Islamic University Islamabad \\ *Corresponding Author:aisha-aaur@yahoo.com
}

\begin{abstract}
This study is an attempt to assess the implementation of women's rights in Pakistan and challenges confronted by women. It also evaluated the contribution of working women's voice against workplace harassment. The population consisted of all the public/private institutions in DG Khan, where women are employed. Total number of 180 respondents was selected as a sample size through purposive sampling method.The results reveal that harassment is routinely practiced at workplace in Pakistan and has genuinely impacted the working women to carryout work effectively. Most of the respondents were aware of women rights but were unaware about protection against harassment of women at the workplace Act, 2010.The research suggests strong interventions to provide training to women and to scrutinize disturbing factors at workplace for women. In the light of the findings it is recommended that the females may know about their rights and employers may adopt the protective measures and anti- harassment policy needs to be organized with the help of employers, managers and legislative bodies.
\end{abstract}

Keyword: Challenges confronted, Workplace harassment, protection, legislative bodies. 


\section{Introduction}

Gender based workplace harassment has existed in one form or another ever since men and began interacting in working and educational environments. However, it is worth nothing that most cases of harassment take place outside the glare of the media spotlight, indeed, harassment on the job is an unfortunate reality.

Women in Pakistan should always accompany other female or inform colleagues during extra hours of working and avoid sitting for late hours in the absence of other staff. When the respondents were asked which tactics they use to tackle the situation, majority believed that complaining or ignoring is the best possible solution. The important themes derived from the responses were complain the administrator ignore, resignation, stress Management Training Peaceful Dialogue with human resource.

Working women in Pakistan are facing great difficulty in their work place due to harassment and discrimination they face in their day to day lives. The researcher has tried to identify causes and reasons of harassment and how it affects the emotional and psychological aspect of working women. Also the laws relating to the harassment with particular focus of Pakistan have also been identified and considered to give protection of working women in their workplace.

The research has been conducted in order to ascertain the great social evil that is harassment which is taking place in almost every society and is deteriorating social norms and cultures. Working women at workplace are the common victim of this menace. Thus as student of sociology and being female the researcher felt the necessity to highlight the issue and bring awareness in the society so that the rising harassment cases could be lessen. The motive of this research moves around the intent that "the more we know and learn the more we grow".

In another institution female pointed out that most male clients and other colleagues attempt or offer favor for harassment. Female lawyers at the court also mentioned that male clients and colleagues harass them by asking personal questions which make them embarrassed. In a bank female working lady pointed out that mostly males drop their visiting card to have relations with them. Some females also shared that peon, guards and other lower staff even they also cause a great tension by verbal and non- verbal threats. Teachers in private school agreed that they are being harassed by the principal or head and male colleagues as well verbally and non-verbally. 
As per Warnalatha (2013)harassment at workplace is to get engaged in such a course of action or conduct against a worker in a workplace that can be termed as unreasonable or unwelcome. This means any inappropriate utterance, action, gesture, body language, staring, coercion, intimidation which causes discomfort and uneasiness for workers is harassment.

Agency for Safety and Health at Work to European Agency (EASHW, 2010) the person who is discriminated on the grounds of natural makeup such as sex, race, disability, migration or religion falls under the category of being harassed. Also any act which causes the coworker to feel ashamed, degradation, humiliation and insult by the management, customers, clients or coworkers are all included in harassment.

Owjin (2008) opines that there has been increasing trend of workplace harassment at work place nowadays. This increasing trend of harassment hits all ranked women by their coworkers, employers and customers. Harassment is not only creating the unrest among the females but it also causes different mental and physical diseases among the females as well.

As per Trade Union Guide (2008) the key to what constitutes 'sexual harassment' is that it is, unwanted, unwelcome and unasked-for behavior of a sexual nature. Sexual harassment is a display of power which is intended to intimidate, coerce or degrade another worker.

In Pakistan the great obstacle for women wishing to join the workforce is harassment that exist in the workplace. Those who join the work force have to face harassment but due to social attitude of blaming women or making her responsible keeps women away to report or talk about their experiences. It is a fact in Pakistan that mostly women become victim of harassment however, man are no exception from this.

\section{Objectives of the Study}

The following were the objectives of the study:

i. To explore the socio-economic characteristics of females with respect to harassment at workplace

ii. To investigate the perception of discrimination and harassment among female working women in DG Khan.

iii. To investigate the causes and consequences of harassment on female's mental health and behavior. 
iv. To suggest the policy recommendations that how the polices should be reformed to address the harassment related issues

\section{Significance of Study}

The study will focus on those aspects of the harassment which have been less investigated at scale by any researcher previously. Purpose of focusing on these aspects is to understand the holistic picture of harassment being faced by working women. The male dominant society and the oppressive environment not only create trouble for common women but also the working class women are special victim of it. The harassment is being observed as a negative part of the society, which needs to be addressed. This study would provide a thoughtful insight into the problems of working women of DG Khan related to nature of perceived harassment they are facing at workplace. This might suggest the policy makers to revise or prepare some policies appropriate to the needs of the working women dealing with such issues at workplace.

\section{Conceptualization of Key Terms:}

Researcher in this study has used the term harassment as inappropriate and uninvited conduct or behavior that might be expected or be perceived to cause offence or humiliation to the coworker. This could be in the form of words, gesture or actions including unwanted verbal and nonverbal which have a tendency to frustrate, humiliate or embarrass the other creating an intimidating and hostile work environment. Researcher in this study has used the term discrimination as any behavior or pattern of behavior that creates an intimidating or offensive work environment or otherwise effects employment opportunity. Discrimination may also be defined as any distinction, exclusion or preference made on the basis of race, color, sex, religion, political opinion, national extraction or social origin, which has the effect of nullifying or impairing equality of opportunity or treatment in employment or occupation.

\section{Theoretical Framework}

The study is based on the Marxists Feminist theory. The theory focuses on the social institutions playing role for the rights of women under the umbrella of capitalist economic system. The theory based that women rights are being oppressed because of the control of men over economic resources and the economic dependency of women on men. 
(DG-Kan)

This theory has different versions however the study relates directly with the ideology of Betty Friedan Mill who was pioneer of second wave feminism. The argument of Betty Friedan Mill is that women are oppressed by men on the basis of sexuality.

\section{Conceptual Model}

The study will investigate the relationship between patriarchy and sexual harassment by exploring the current relations between the men and women at workplace on the basis of their economic and social status. Moreover it will explore the root causes of harassment faced by women by their male colleagues.

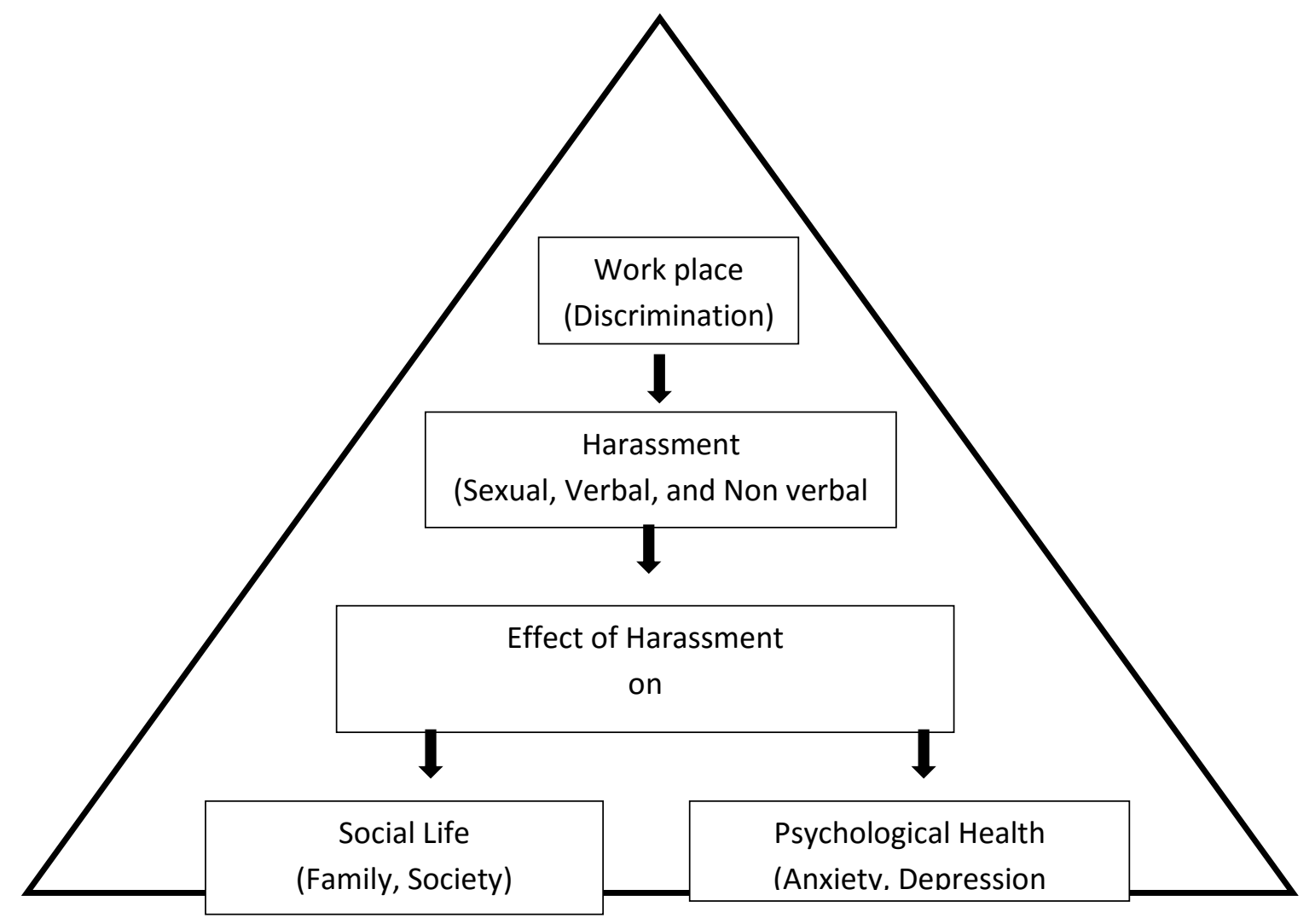

\section{RESEARCH QUESTION:}

How the harassment impacts female's social and psychological life?

\subsection{HYPOTHESES:}

In order to validate the objectives with regard to relationship between discrimination and harassment the following hypotheses were tested:

i. Higher the discrimination at work place higher will be the harassment 
ii. Female workers experiencing higher degree of harassment report more emotional problems than those experiencing lower degree of harassment.

iii. Female workers experiencing higher degree of harassment report more social problems than those experiencing lower degree of harassment.

\section{Variables}

INDEPENDENT VARIABLE

DEPENDENT VARIABL

Harassment

Workplace

Emotional Instability

\section{INDICATORS OF VARIABLE}

\section{Discrimination at Work Place (Independent Variable)}

i. Sitting arrangement of male and female

ii. Limited social interaction among male and female colleagues

iii. Pay Gap

iv. Status Gap

v. Family Status

\section{Effect of Harassment on Mental Health (Dependant Variable)}

i. Mood Disorder

ii. Lack of concentration

iii. Agitation

iv. Anger Behavior

\section{Effect of Harassment on Emotional Instability (Dependant Variable)}
i. Anxiety
ii. Frustration
iii. Depression

\section{Universe}

In the present research the researcher would focus on District Dear Ghazi (DG) Khan. DG Khan would be the study area of the present research.

DG Khan consists of three Tehsils: 

i. Tunas Sharif
ii. DG Khan
iii. Tribal Area

Being a district of Punjab Dera Ghazi Khan has great importance as it is located in the centre of South Punjab where all four province boundaries touch to it. The weather in this area are extremes where temperature soars in summer to 50 degree Celsius and in winter it sometimes fall below 1 degree Celsius with inadequate rainfall.

\section{Brief History}

During British period Dera Ghazi Khan Tehsil was declared a subdivision. As per 1901 census of India the population was 193,744, compared with 177,062 in 1891.As per 1998 census population of DG Khan is 1,643,118. Vast variety of Punjabi dialects are spoken by the inhabitants of DG khan District, although few of these dialects are "Saraiki", but because of good and loving nature of people there is no discrimination or hate among the residents. Languages spoken are Derawali, Majhi or standard, Raangri, Thlochi, Khetrani. Other languages include Baluchi and Pashto.Urdu is widely spoken and understood by all being mother tongue and national language.

\section{Sample Technique}

Convenient technique has been employed for the collection of data. Sampling has been used to collect the data under government and private institutions e.g. educational, finance, health, social welfare etc. 180 respondents have been selected as a sample size.

\section{Sample Size}

The sample was collected under convenient sampling as per availability and given informed consent .

The present research consists of 180 female respondents.

\section{Data Collection Tool}

Questionnaire method was used for the collection of data which will comprise on open ended and close ended questions. 


\section{Data Collection}

Data was collected by the face to face interview and a questionnaire was administrated which would be conducted after the permission of the respondent. All research ethics were considered for the purpose of research. Time was taken before conducting the interview. Before the interview the researcher also did chit-chat with the respondent just to make them comfortable and easy for the taking of all information.

\section{Field Experience}

In order to collect the data researcher visited various organizations where females are working. In most cases females appreciated the effort the researcher is doing to highlight the issue of harassment which most of the working women face at their workplace.

In some cases respondents hesitated to give their responses against the questionnaires as they felt that it could be used against them. Also many respondents simply declined to give or share any such information related to their personal experiences in the working place owing to fear to lose their job or reputation.

\section{Research Design}

Total respondents which have been taken from the research are 180. Data was collected by the self-developed questionnaires which were personally administered. The intent of using the questionnaire method was to give the respondent the adequate time to think before answering to the statements on the prevalence and nature of harassment experienced.

The sample size of 180 respondents was considered to be sufficient to get a idea of the perceived impact of the key areas of the research on harassment. The adequacy of the sample was further confirmed by using the Chi-Square technique.

\section{Data Analysis}

Research has been analyzed by applying Statistical Package for Social Sciences called SPSS. Different tests were also applied for the research

Table 1: Perceived factors due to which discrimination takes place

\begin{tabular}{|c|c|c|}
\hline Factors & Response & Percentage \\
\hline Education & 30 & $23 \%$ \\
\hline Race & 10 & $8 \%$ \\
\hline
\end{tabular}


(DG-Kan)

\begin{tabular}{|c|c|c|}
\hline Ethnicity & 9 & $7 \%$ \\
\hline Religion & 6 & $5 \%$ \\
\hline Age & 7 & $5 \%$ \\
\hline Disability & 14 & $11 \%$ \\
\hline Gender & 12 & $9 \%$ \\
\hline Marital Status & 6 & $5 \%$ \\
\hline Job Status & 10 & $8 \%$ \\
\hline Personal Appearance & 9 & $7 \%$ \\
\hline Life Style Status & 8 & $6 \%$ \\
\hline Hereditary makeup & 8 & $6 \%$ \\
\hline Total & 129 & $100 \%$ \\
\hline
\end{tabular}

Table 1 determine the factors on which the females face discrimination $23 \%$ on the basis of education, $8 \%$ on the racial ground, $7 \%$ on ethnicity, $5 \%$ on religion, $5 \%$ on age, $11 \%$ on disability, $9 \%$ on gender, $5 \%$ on marital status, $8 \%$ on job status, $7 \%$ on personal appearance, $6 \%$ on life status and $6 \%$ they have been discriminated on the basis of hereditary makeup.

Table 2: Opinion of working women about the occurrence of harassment at workplace

\begin{tabular}{|c|c|c|}
\hline Response & Sub Total & Percentage \\
\hline Yes & 176 & $98 \%$ \\
\hline No & 4 & $2 \%$ \\
\hline Total & 180 & $100 \%$ \\
\hline
\end{tabular}

When asked whether harassment takes place at workplace, most of the respondents answered yes. As per the table above those who responded yes were $98 \%$ whereas only $2 \%$ responded to it as No.

Research cited that harassment among women of all ages, races, occupations, income levels, and marital statuses woman and not only to just specific kind of women.(Frely;1978)

Table 3: Harassment types faced by working women in the organization

\begin{tabular}{|c|c|c|}
\hline Harassment Nature & Responded Affirmatively & Percentage \\
\hline Verbal & 172 & $96 \%$ \\
\hline Non Verbal & 8 & $4 \%$ \\
\hline Total & 180 & $100 \%$ \\
\hline
\end{tabular}


As per this table $96 \%$ females faced verbal harassment and $4 \%$ females faced non-verbal harassment.

As per the research the unwelcome sexual conduct and concealing phenomenon is the part and parcel of almost all professions. (Hunt, Dvidson, Fielden and Hoel, 2007)

Table 4: Reporting of harassment facilitated/encouraged women at workplace

\begin{tabular}{|c|c|c|}
\hline Response & Sub Total & Percentage \\
\hline Yes & 32 & $18 \%$ \\
\hline No & 148 & $82 \%$ \\
\hline Total & 180 & $100 \%$ \\
\hline
\end{tabular}

When asked whether reporting incident of harassment occurred at workplace was facilitated or encouraged most of the respondents answered as 'No'. As per the table above those who responded yes were only $18 \%$ whereas $82 \%$ responded to it as 'No'.

Table 5: Reasons for responding about reporting harassment facilitated/encouraged

\begin{tabular}{|c|c|c|}
\hline Responses & Sub Total & Percentage \\
\hline Management/Employer & 101 & $68 \%$ \\
\hline Union/Association & 23 & $16 \%$ \\
\hline Own family/friends & 10 & $7 \%$ \\
\hline Colleagues & 12 & $8 \%$ \\
\hline Any Other & 2 & $2 \%$ \\
\hline Total & 148 & $100 \%$ \\
\hline
\end{tabular}

As per the above Table 5 it is observed that out of 148 who had responded No on previous table 20 (a), $68 \%$ believe that not facilitating or encouraging report of workplace harassment was due to management/employer, $16 \%$ believe that union/association is responsible, $7 \%$ believe that is due to own family/friends, $8 \%$ say that is due to colleagues and $2 \%$ thought of other reasons working behind it.

Table 6: Knowledge about the harassment bill which has been passed by the National Assembly in 2010 
(DG-Kan)

\begin{tabular}{|c|c|c|}
\hline Response & Sub Total & Percentage \\
\hline Yes & 24 & $13 \%$ \\
\hline No & 156 & $87 \%$ \\
\hline Total & 180 & $100 \%$ \\
\hline
\end{tabular}

This Table 6 demonstrates that just 13\% females have a knowledge about the harassment bill while $87 \%$ females don't know about the bill. So we may say that most of the working women are not aware about their rights related to workplace harassment.

Table 7: with regard to social relations harassment give rise to lose

\begin{tabular}{|c|c|c|}
\hline Responses & Sub Total & Percentage \\
\hline Ties with the family & 31 & $17 \%$ \\
\hline $\begin{array}{c}\text { Lose your Friend } \\
\text { members and relative }\end{array}$ & 19 & $11 \%$ \\
\hline Feel Lonely/Isolation & 43 & $11 \%$ \\
\hline $\begin{array}{c}\text { Aggressive behavior with the } \\
\text { family }\end{array}$ & 33 & $18 \%$ \\
\hline Loss of interest in Outing & 14 & $8 \%$ \\
\hline No Interest in Shopping & 11 & $6 \%$ \\
\hline None of Above & 9 & $5 \%$ \\
\hline Total & 180 & $100 \%$ \\
\hline
\end{tabular}

On asking what social relations harassment give rise to among the working women, almost all believe that this give rise to issues pertaining to ties with the family, losing friends, lack of interaction with family members and relatives, lonely/isolation, aggressive behavior, lose of interest in outing and shopping.

\section{Recommendations}

i. Make sure that staff are aware of the grievance and resolution techniques;

ii. Wherever the incident of harassment takes place regular survey and probing is needed;

iii. Revising the policy of harassment, complaints mechanism and the training;

iv. The legal access for the women especially in the case of facing the violation of women's right; 
v. Though present research was done with utmost input and intent of best possible accuracy there were still certain weaknesses identified at the end of the study.

vi. Primarily the sample used in this present research was restricted and was collected from only district Dera Ghazi Khan that limits the ability to generalize the result to the larger population. Gathering data from a large and diversified sample would yield more reliable results.

vii. Due to the sensitivity of the topic females hesitated to share the facts

viii. Heads of the organizations also not allowed to enter and collect the information as they thought this would be causing to defaming the institution.

ix. Females afraid to share the information as this information might be disclosed

x. Due to the oppressive culture of the area researcher faced many difficulties during the collection of the data

\section{REFERENCES}

Aggarwal, A. (1994). Dispute resolution processes for sexual harassment complaints, in Canadian Labour and Employment Law Journal, Scarborough, Ontario: Vol. 3, No. 1, pp. 61--93

Alexanderson, K \& Hensing, G. (2004). More and better research needed on sickness absence. Scandinavian Journal of Public Health, 32, 321--323

Barkley, B.H, \& Mosher, E.S. (1995). Sexual and Hispanic culture: Counseling with Children and their parents, Journal of Sex Education and Therapy, 21, 255-257

Bargh, J.A. \& Raymond, P. (1995). The baive misuse of power: Non conscious source of sexual harassment. The Society for the Psychosocial Study of Social Issues 15: 85--95

Cleveland, J.N; \& Kerst, M.E. (1993). Sexual harassment and Perception of Power: An underarticulated relationship; Journal of Vocational Behavior, 42.49---67

Cammaert, L. (1985). How widespread is sexual harassment on campus? International Journal of Women's Studies, No. 8, pp. 388-397

Faley, R. (1982). Sexual harassment: Critical review of legal cases with general principles and preventative measures. Personal Psychology, 35, 583--595

Falardean, R. M.(1994). When "no" is not enough: Sexual harassment and the CanadianHuman Rights Act. INL.Geller-Schwartz (Ed.), From awareness to action (pp.45-50)

Fornes, J. M. C. J. M. C \& M. Gili. (2010). Psychological harassment in the nursing workplace: an observational study. Australian J. Arch Psychiat Nurs, 25(3): (p.185-194) 
Workplace Harassment of Working Women: A Case Study Of District Dera Ghazi Khan

(DG-Kan)

Fornes, J. M. Castello \&. Gili. M(2010). Psychological harassment in the nursing workplace: an observational study. Australian J. Arch , 25(3): (p.185-194)

Fitzgerald, L.F., Weitman, L.M., Gold, Y. \& Ormerod, M. (1988).Academic harassment: sex and denial in scholarly garb. Psychology of Women Quarterly, 12, 329 - 340

Fitzgerald, L. F., \&Ormerod, A. J. (1991). Perceptions of sexual harassment: The influence of gender and academic context. Psychology of Women Quarterly, 15, 281-294

Fitzgerald, L. F, \&Shullman, S. L. (1993). Sexual harassment: A research analysis and agenda for the 1990s.Journal of Vocational Education, 42, 5-27

Fitzgerald, L.F. (1993). Sexual harassment: violence against women in the workplace. American Psychologist, 48, 1070- 1076

Gutek \& Koss, M.P. (1993). Changed women and changed organizations: consequences of and coping with sexual harassment: Journal of vocational behavior, 42.28-48

Keita G \& Hurrell J, editors. (1994). Job Stress in a Changing Workforce: Investigating Gender, Diversity, and Family Issues.Washington, D.C: American Psychological Association; pp. $55-73$

Krieger, N. (1994). Epidemiology and the web of causation: has anyone seen the spider? Social Science \& Medicine, 39(7), 887-903

Kohlman, M.H. (2004). Person or Position? The Demographic of Sexual Harassment in the Workplace. Equal Opportunities. International Vol.23, No. 3/4/5

Lafontaine, E; \& Tredeau, L. (1986). The frequency, sources, and correlates of sexual harassment among women in traditional male occupations. Sex Roles 15. 433--442

Mitchell, M.S and Ambrose, M.L.(2007).Abusive Supervision and workplace Deviance and the Moderating effects of negative reciprocity beliefs. Journal of applied Psychology, 92( 4), 1159-1168

Pierce, C.A. ( 2003). Romantic relationships in organization: Atest of a model of formation and impact factors. Management Research, 161--169

Padavic, I. \& Orcutt, J.D. (1997). Perceptions of sexual harassment in the Florida Legal System: A comparison of dominance and spill over explanations, Gender Sociology, 11(5) 682--698

Tangri, S.S; Burt, M.R, \& Johson, L.B. (1982). Sexual harassment at work: Three explanatory models. Journal of Social Issues. 38.33---54 
The European Transformation of Harassment Law: Discrimination Versus Dignity, Columbia Journal of European Law, Vol. 9, 241 (2003)

Uggen, Cs \& Blackstone. (2004). Sexual harassment as a gendered expression of power, American Sociological Review, 69, 64--92

Veale, C and Gold, J. (1998). Smashing in to the glass ceiling for women manager's, Journal of Management, Vol. 17, pp; 17--26 